\title{
Electric Propulsion for the U. S. S. New Mexico-III"
}

\author{
The Main Control Equipment, Centralized and Flexible \\ By C. T. Hentschel
}

[Continded from Scientific American Supplement for Jone 21, No. 2268, Page 397]

The development of a new Idea, such as the electric propulsion of vesels, naturally brings with it the necessity for designing suitable auxiliary apparatus; and this is in the fullest sense true of the electrical propulsion control equipment for the U.S.S. New Mexico. At the beginning it was realized that, if speed o action and intelligent interpretation of commands were to be attained, the control of the main switching, the generator field adjustment, and the steam adjustment must be centralized at one point. This brought about the design of the propulsion control cell ${ }^{1}$ which contains all the means of control and switching (with the exception of the gene r a t or disconnect-
ing switches) for the two turbine-generators and the four propulsion motors. (Fig. 1.)

The list of devices includes :

Two generator dis connecting switches for isolating the generators and providIng a means for changing the generator connections.

One bus-tie switch for connecting the opposite pairs of motors to either generator or for separatIng them when it is desired to use two generators.

T $w 0$ reversing switches for changing the direction of rotation of the motors for the purpose

of reversing the direction of travel of the ship.

Two pole-changing switches for changing the pole connections in the motors for different conditions of operation.

Two operating levers and mechanisms for reversing Two operating levers for pole changing.

Four motor disconnecting switches for isolating the motors.

Two bulkhead panels (bulkhead plercing).

Two field-control levers.

Two field switches.

Two booster-field rheostats.

Two speed-control levers.

Two steam-llmit levers.

Two steam-limit indicating switches.

A complete set of interlocks, both electrical and mechanical, to safeguard the operator and also to produce certain sequences of operation of the different devices necessary for the proper control of the ship.

Figure 2 shows a diagram of the arrangement of cables and switches in their relative order.

\section{THE CONTROL CELI.}

The control cell, shown partially assembled in Fig. 3 , is rectangular in shape $16 \mathrm{ft} .8 \mathrm{in}$. wide, $9 \mathrm{ft}$. deep, and $111 / 2 \mathrm{ft}$. high. It is built of 4-in. channels and $11 \%$ ft. unit in order to withstand the vibrations due to unit in order to withstand the vibrations due to
machinery and propellers and also the shocks re sulting from gunfire.

The cell is firmly anchored to the floor of the con trol room and machinery deck and it has no further supports. It is located in the center line of the ship and has ample passages around it. The outside surfaces are covered with steel basket-weave grille, except in the places occupled by the instrument, gauge, and control panels.

The cell is divided by a fore-and-aft aisle, shown in Fig. 4, into port and starboard sections, each sectinn controlling a generator and two motors; and it is further divided by a thwartship aisle, Fig. 4, forming a natural division between the reversing and the pole-changing switches. This arrangement permits

-Reprinted from General Eleotrio Reviewo.

"'Controlling the Propulaton of the Nero Meatco, of ready access to all the devices. Grille doors are installed on the port and the starboard sides. The doors are provided with magnetic locks energized from the field circuits, so that the cell cannot be entered unless the field breakers are open. This protects the operators against contact with the high-tension circuits.

The cell is open at the top but a steel roof is installed about two feet above and extends about 12 inches on all sides. Without interfering with the ventilation, this roof protects the cell against the possibility of that roof protects the cell against the possibility of water dripping from above and the acci- complete throw-over with only $90 \mathrm{deg}$. of actual movement. There are two laminations per pole. The poles are connected in pairs by a cross-head which, by means of couplings and a wooden rod, is connected to a crank keyed to the operating shaft of the switch. The hinge blocks are connected in pairs by coppe bars arranged for cable connections to the main busbars at the top of the cell. The studs extend through insulators securely locked to a cast-metal base, which is bolted to the fore-and-aft bulkheads forming the boundarles of the control room. In this manner, the bour in this manner, the cable entrance panel through the watertight bulkhead be tween the turbine and the control compartments.

The switches are mounted on end witl the shafts vertical and are operated by means of a stout means of a stont
hand lever which is hinged at its ful crum so that it can be let down into a vertical position when not in use, thus preventing its obstructing the passageway on either side of the contro cell.

The shaft is provided with a notcher quadrant and a roller pawl actuated by a heavy spring. This gives the operator an indication when

Fig. 1-Main control switchboard and cell

allowing sufficient headroom for operation, are mounted the four main bus bars which consist of two laminations of 5 by $1 / 4-$ in. copper and which are located in the forward half of the cell. The other half of the cell contains the motor buses in the same plane. These consist of two laminations of 2 by $1 / 4-1$. bars.

\section{INSULATION.}

The problem of insulation was a serious one. On account of the vibration due to running machinery and to the more serious matter of gun shock, the service on a battleship is very severe. It was obvious that porcelain could not be used, and therefore it was de-

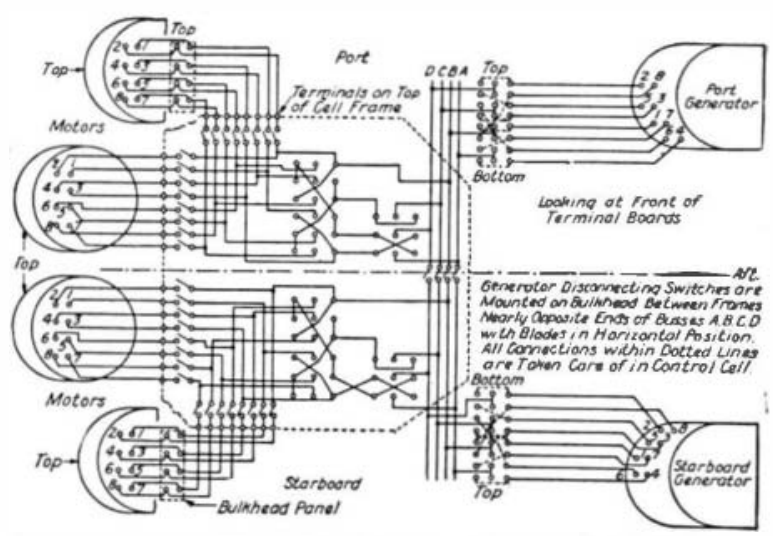

Fig. 2-Diagram of wiring and switches between of the New Mexico
of

cided to uttlize a molded compound insulation. Two types of insulators were produced; one for use in insulating the studs of the switches, and the other for supporting the buses and connections. [These are not figured here.]

\section{GENERATOR DIBCONNECTING SWITCHES.}

The generator disconnecting switches, Fig. 5, are eight-pole, double-throw and are rated 5,000 volts, 1,200 amperes. In addition to their serving the purpose of isolating the generator, they are used for changing the connections in the greater windings.

The switch blades are L-shaped which permits he has reached the open or closed position of the BUS-TIE SWITCH.

The bus-tie switch, Fig. 6, is four-pole, single-throw and is rated 5,000 volts, 2,400 amperes. It is used to tie the port and starboard generator buses together when only one machine is used to drive all the motors. The blades of the switch consist of two lamination per pole, which operate between contact clips set into suitable blocks attached directly to the bus bars. They are in turn connected by means of couplings and wooden insulating rods to bell-cranks keyed to the operating shaft.

$\Delta$ hand lever, directly attached to the shaft and operating in the thwartship aisle, provides a means for throwing the switch, but, owing to the magnetic locks on the cell doors, it is not accessible until the field circuit has been opened.

REVERSING AND POLE-CHANGING SWITCHES.

The operation of reversing and pole changing is accomplished by the use of double-throw, oil circuit breakers, Fig. 9, made up in single-pole units each having a capacity of 1,500 amperes at 5,000 volts. The reversing switch is triple-pole, each pole consisting of two units connected in multiple. They are mounted directly behind the front wall of the cell and are separated by the fore-and-aft aisle as shown in Fig. 3 . Inter-connections between the switches, and from the switches to the main busbars directly above, are made with heavy copper bars. The studs are insulated from the frame by means of bakelite compound insulators. The contacts are of the brush type and are provlded with secondary arcing tips on the brush, and burning plates on the fixed blocks. All these parts are easily renewable. The contact arms are hinged to the center stud and the carrying capacity is maintained by flexible copper connectors fastened between the center stud and the brush.

Each brush lever is connected by means of an impregnated wood rod and a coupling to the switch mechanism which is mounted on the cover frame and the mechanisms are connected six in tandem across the tops of the switches. These six mechanlsms are operated in unison by means of a toggle arrangement 
which is connected which is connected
to the bell-crank that communicates with the operating mechan is m as shown in Fig. 7.

Each breaker unit has its individual oil tant vidual ofl tank for the handling of which an adjustal)e platform
been installed. The pole-changing switches are identical with the reversing switches, hut they switches, in single capacity and are connected to the motor buses mounted a b o ve them and also to the reversing switches.

OPERATING MECHANISM. The switches are operated from the front of the board by means of the large levers shown in Fig. 7. The two inner levers are for reversing and the two outer ones for pole changing. They are pivoted on the pedpivoted on the pedestals and commu-
nicate with the oil

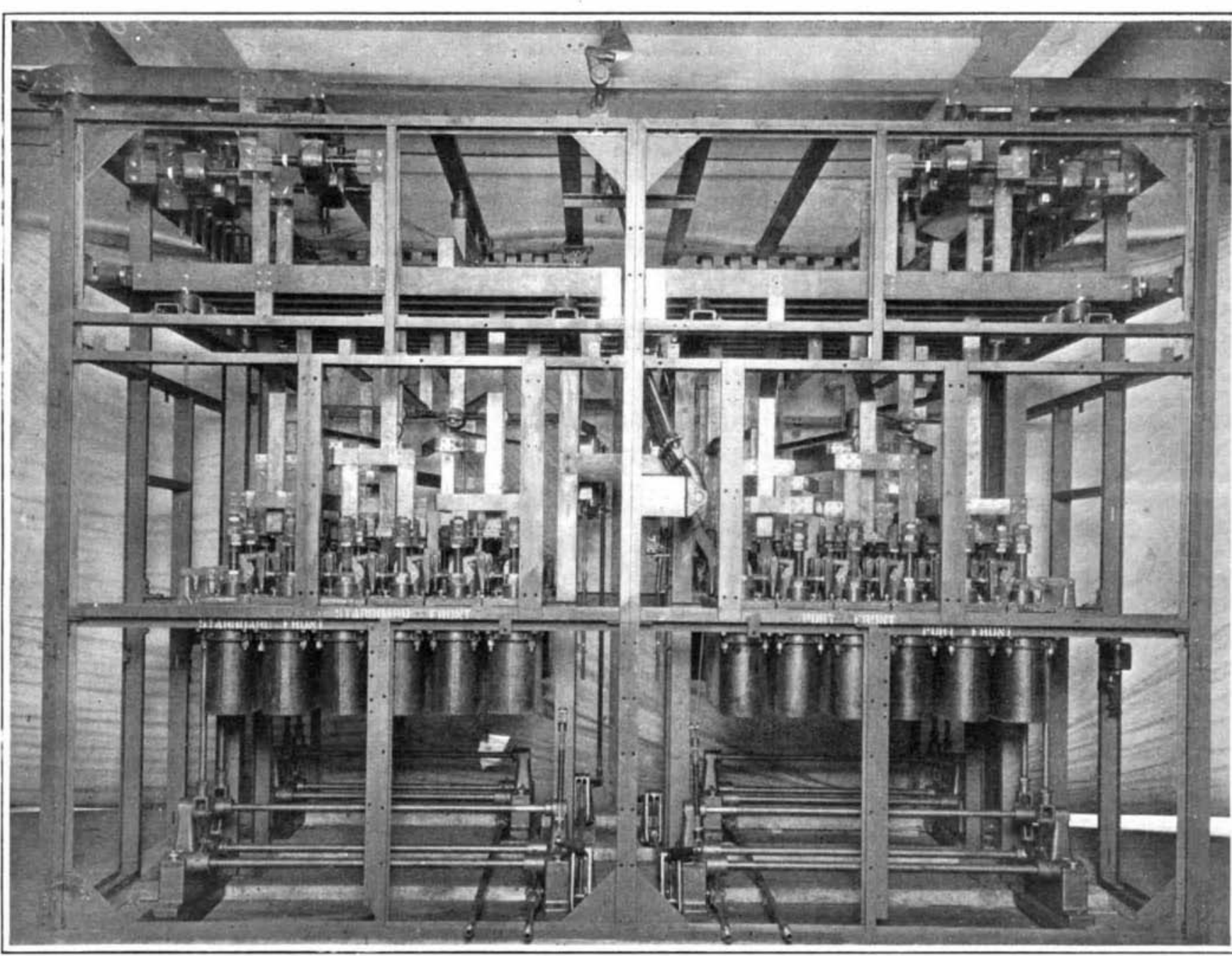

Fig. 3-View (front) of control cell partially assembled, showing fore-and-aft aisle

Ing lever operating in the notches, thus giving a ready means for fixing the lever at any desired position. The notches in the quadrant $c 0 v$ only the range between maximum buck and normal field, so that the lever cannot be locked in the overexcitation position. The booster fleld rheostat is mount. ed in the cell structure on either side of the foreand-aft aisle near the rear wall.

The field switch is a double-pole, solenoid - operated circuit breaker rated 400 amperes 250 volts. It is equipped with magnetic blowout colls at the secondary arcing tips and with a trip coil for connection to the contacts of the balance relay, Fig. 9.

SPEED CONTBOL.

Speed control is accomplished by adjusting the amount of steam

circuit breakers through a pipe and crank mechanism to the operating shafts located under the breakers and thence through the vertical pipe to the switch mechan isms. The levers have three positions, the vertica one being "off."

MOTOR DISCONNECTING SWITCH.

The four motor disconnecting switches, Fig. 8, are eight-pole, single-throw and are rated 5,000 volts, 600 amperes. They are mounted at the top of the control cell, one on each side for the port and starboard outboard motors, and two at the back for the inboard motors which are located directly back of the cell The switches are of single-blade construction, each blade being connected by means of couplings, insulating rods, and cranks to a common shaft for simultaneous operation. They are back connected through bakelite insulators and are operated by a handle on the outside which can be reached from the deck by a switch hook.

The lower studs are connected to the motor buses while the upper studs are led out at the top of the cell over insulators by means of connection bars and terminals to the motor cables.

A latching arrangement on the hand lever prevent opening the switch under vibration. This latch automatically relieved by the normal use of the switch hook. The switch is provided with a sheet-iron cover so that accidental contact with live parts is imposible.

BULKHEAD PANELS

Two bulkhead panels are provided to carry the motor leads through the port and starboard bulkheads. These consist of a cast composition base mounting eight bakelite insulators, having a copper stud in each firmly locked by means of clamping nuts at each end. Terminals on each end provide means for attaching the motor cables and the connections to the motor disconnecting switches.

FIELD CONTROL.

The control of the generator is accomplished by the use of a booster set which is used either to buck or to boost the main field.

The booster set is regulated by means of the boosterfield rheostat, which is controlled by the feld-control lever, shown in Fig. 10.

Pulling the lever out from the board 30 degrees closes the circuit of the solenoid operating the field switch (which is mounted on the exciter board) and places the rheostat switch in the maximum-buck poition. Continuing the movement of the lever anothe 30 degrees, which covers 28 steps of resistance, progressively relieves the "buck" and allows normal excitation to be impressed on the main generator. The following and last 30 degrees of motion produces a gradual boosting of the field over a range of 28 more steps of resistance to the maximum point. This excess

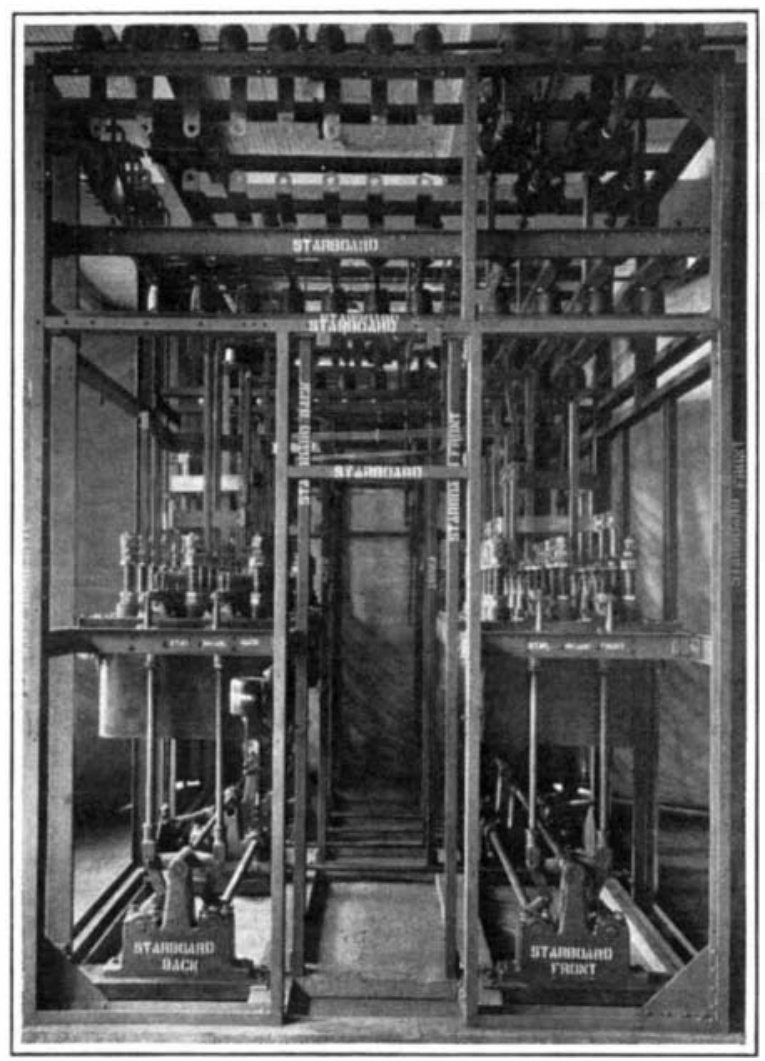

Fig. 4-Starboard side of control cell, showing transverse aisle

field current is necessary for pulling the motors into step, but it must not be maintained longer than neces sary. To insure this condition, the lever is provided with a spring-return action augmented by a stout spring and lever arrangement in the pipe mechanism, near the rheostat, which returns the lever mechanism an rheostat switch automatically to the normal excitation position when the handle is released.

The hand lever is made of polished steel and straddles a notched quadrant. It is provided with a latch- flowing to the turbine, and it consists of two control levers for each turbine, one for speed control and the other for the purpose of limiting the number of open turbine valves.

The speed-control or steam lever, Fig. 10, is mounted at the side of the field-control lever and is similar in design. Its throw is limited to 45 degrees and it has notches corresponding approximately to $1 / 4,1 / 2,3 / 4$, and full speed. In addition to those, to provide a means for obtaining any intermediate adjustments by small increments, a hand wheel and screw arrangement is installed as shown. A four-spoked locking wheel is provided on the screw for holding the adjustment when made.

At the back of the board the lever ends in a crank and coupling which are attached to a shaft und a crank mechanism by means of which the motion of the speed lever is communicated to the operating levers at the turbine.

\section{STEAM LIMITING LEVERS.}

The steam-limit lever, Fig. 10, is mounted belo the speed lever and is similar in design, except that it is smaller. It has a throw of 90 degrees and is equipped with a spring arrangement at the hinge by which the lever is thrown into full-valve position when the speed lever is thrown into the off-steam position. This is accomplished by means of a connecting rod between the two which actuates the tripping mechanism at the proper time. The quadrant has 20 notches into which the heel of the latching lever fits when released. This gives 20 coarse steam adjustments which can be made independently of the speed lever and without interfering with the action of it.

This lever is connected by a shaft mechanism, similar to the one employed for the speed lever, to the valve control arm at the turbine.

STEAM-LIMIT INDICATING SWITCH.

Installed at the end of the steam limiting mechan ism and on the valve-limit hook is the steam-limit in dicating switch. It consists of a light switch arm installed in the hook and operated by the valve limitin arm in the hydraulic control mechanism. Here roller operates upon the collapsible plate and link arrangement which is connected to the switch arm, causing the arm to move its contact over a set of contact buttons suitably insulated. The contact buttons are connected to the 125-volt, direct-current circuit and to a set of indicating lamps on the control board.

INTERLOCKS.

When a large number of devices, such as those described, are gathered together, it is readily discernible 
that means must be provided to prevent the making of mistakes and to confine operations to their proper sequence, therefore the very elaborate set of mechanical interlocks, described in the following, were designed and applied to the various devices:

The Generator Disconnecting Switches

(1) Must not be opened or closed when energized. This operation is prevented by the magnetic lock, Fig. 5 , which interferes with the rotation of the shaft and which is actuated by the field circuit when the fleld switch is closed. This means that the field-control lever must be placed in the vertical (field-off) position before a disconnecting switch can be moved.

(2) Must not be closed when the bus-tie switch and opposite generator disconnecting switch are both closed.

(3) Must not be closed in the high-voltage connection when the bus-tie switch is closed, Fig. 6.

(4) Must not be closed in the low-voltage position when the bus-tie switch is open, Fig. 6.

T'he Bus-tie Switch

(5) Must not be closed when both generator disconnecting switches are closed, Fig. 6.

(6) Must not be opened or closed when energized.

This protection is secured by the magnetic lock on the This protection is
cell doors which cell doors which
prevents them from being opened unless the field circuit is "off."

The Reversing and Pole-changing Switches

(7) Are electrically locked by the locking magnet, Fig. 7, so that they cannot be opened until the line current has dropped to a predetermined value as governed by the undercurrent relay.

The coils of this relay are connected to the secondary circuits of the linecurrent transformer and its contacts er and its contacts operate the mag netic lock through
the 125-volt excitation circuit.

I'he Reversing

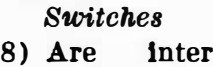
locked locked with the
pole - ch a ng ing pole - c h a n ging
switches by means of the interlock box of the interlock box
shown in Fig. 7, shown in Fig. 7,
so that the former may not be thrown in the astern position unless the polechanging soltches chang ing switches are in the 36-pole connection a nd,
c onversely, the pole - ch a ng ing

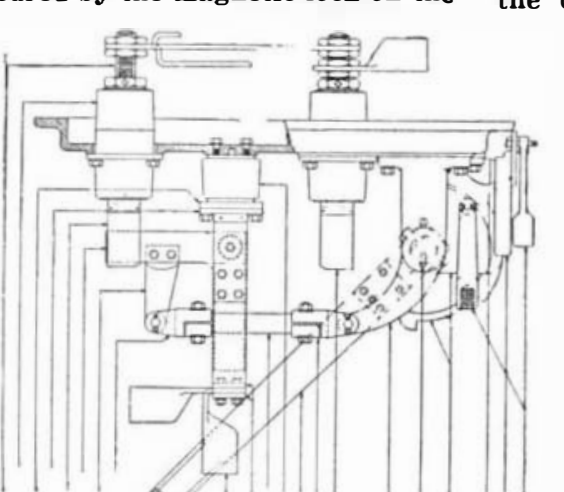

switches cannot be thrown in the 24-pole connection when the reversing switches are in the astern position. The Reversing and Pole-Changing Switches

(9) Are also locked by the field-control lever, so that they cannot be operated unless the field lever is in the vertical (field-off) position.

(10) Are further interlocked cross-ship with the field lever on the opposite side, so that they cannot be operated when the field switch is closed.

This interlock is shown in the lower part of Fig. 10 and consists of a shaft rotated by means of the pipe and bell-crank arrangement connected to the bus-tie switch operating a shaft as shown in Fig. 6.

The rotation of this shaft causes an extension of a set of springs attached to a second and a third shaft which are connected by links to the locking cams of the reversing and pole-changing switches on both sides.

The shafts, however, lock and cannot rotate until one of the field levers has been pulled out. The locking of the port switches is subject to the starboard field lever and vice versa; and the whole interlock is made inactive by the opening of the bus-tie switch. I'he Motor Disconnecting Switches

(11) Must not be operated when alive, and to pre- vent this they are equipped with a locking magnet, Fig. 8, connected to the field circuit.

ield-control and Steam-control Lever

(12) The field-control levers are interlocked with their respective reversing and pole-changing switches, so that these switches cannot be operated when the feld lever is in the field-on position.

(13) The field-control levers are also interlocke with their respective speed-control lever, so that the field may not be taken off the generator without firs pushing the speed-control lever to a low-steam position.

(14) The speed-control lever is interlocked with the field lever, so that only a limited amount of steam may be admitted to the turbine before the field circuit is closed.

(15) The speed-control lever is interlocked with the steam-limit lever, so that whenever the speed leve is moved to the off position the steam-limit lever is tripped to the full-valve position.

\section{The Color of Water*}

\section{By Wilder D. Bancroft}

"THERE is still another point which calls for attention. If the yellow color of a liquid is due to the suspension of a certain number of solid or liquid particles, the color should disappear as the particles sink; it taught us to recognize. To test this point experimentally, I have made at $18^{\circ}$ a nearly saturated solution of pure calcium chloride containing no iron. In the observation tube this solution was a beautiful greenish-yellow. When diluted with water or when the thickness of the layer was decreased, the green became more marked. An almost saturated solution of pure magnesium chloride has shown a very pure golden yellow. A saturated solution of equally pure sodium chloride was wonderfully transparent and had a mag nificent chrome-green color. I have not examined solutions of other salts because of the difficulty of getting them really free from iron. I believe nevertheless that it is proved that the yellow color produe by dissolving a salt depends less on the amount of salt dissolved than on the nearness of the solution to the crystallization point. Small amounts of a slightly soluble salt will produce the same effect as large amounts of a more soluble substance. To test this directly, I boiled pure, blue, distilled water for some time in a glass flask. It is known that glass is slightly soluble in water. When the cooled water was poured into the observation tube, it proved to be completely opaque. After some hours a deep yellow light passed and at the end of two days it became green and remained so. Its clearness was then very great, but the s mall amount of transparent $m$ aterial which which had been taken from the
glass was enough to color it green. "We can now show how the observed facts may be used to account for the colors of natural waters. We start with the assumption that $n$ sufficiently thick layer of absolutely pure water has a beautiful blue color. If small less salts are in less salts are in true solution, the color of the water will remain blue: but if the water contains greater or lesser amounts of a nascent precipitate the light passing through the water will be a more or less deep yellow. There may even come a point at which no light will pass and the liquid will appear opaque ; in other words, black. The yellow light will necessarily blend with the blue of the water to form

Fig. 7-Reversing and pole-changing oil circuit breakers with operating mechanism should be ephemeral. If this were true, the suggesgested explanation of the different colors of natural waters would present a real difficulty; but this is not the case. I have allowed a turbid lime-water solution to stand for seventeen days in the observation tubes. At first no light came through, but after some time the lime began to precipitate in the tube and the liquid became more and more green. At the end of twelve days the water was so clear that one could see through the tube a light pencil mark on a piece of paper. The color of the water was green, nevertheless, and remained so. It was evident that I was dealing with a solution of lime in water without any solution of lime in water without any real suspension to form a green with the blue of the water. Turbid waters containing bicarbonate of calcium or of barium in suspension show the same phenomenon, whence it follows that the resistance to the passage of light manifests itself also when light pases through saturated solutions where a precipitate is ready to form. This last might be called a nascent precipitate by analogy with the nascent clouds which Tyndall has - Continued from Scientific A Merican Bupplemint, No. 2268, page 395 . a series of tints which will vary with the amount of yellow from greenish-blue through bluish-green to green. If there is too much yellow, the blue will disappear and the water will be a brown-yellow or even darker.

"Let us see now how these conditions may be realized in nature. The sparingly soluble substances in the natural waters, which may appear as nascent pre cipitates, are for the most part calcium carbonate, magnesium carbonate, silica, aluminum silicate or aluming. It is not necessary to consider the more soluble substances such as the chlorides and sulphates of sodium and magnesium because they do not occur in sufficient quantities to produce the effects in question. A blue water like the Lake of Geneva, or, better, lik the Lake of Achen in the Tyrol, must have the calca reous matter more completely dissolved the more blue the water is. There must therefore be a sufficient amount of carbon diozide to form calcium carbonate. A green water, on the other hand, like that of the Lake of Constance, must have the calcareous matter in a less perfect state of solution, which must be due to there being relatively less carbon dioxide in the water. It is interesting to note that these predictions are 